\title{
L'artisan de la réconciliation
}

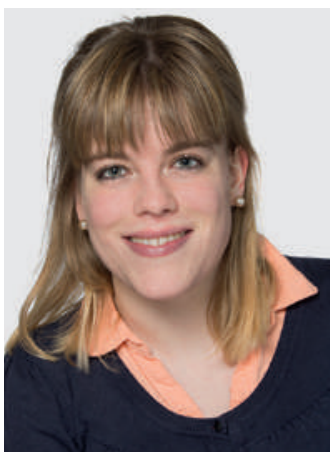

Isabel Zwyssig

A propos de Nelson Mandela, voir également l'article de Jean Martin à la page 1869 de cette édition.

\section{Bibliographie}

1 Mandela N. Un long chemin vers la liberté. Paris. Editions L'Ecole des loisirs; 1996.

2 Voir également à ce sujet l'interview récemment publiée dans le BMS du secrétaire général de la World Medical Association: Kesseli B. «Nous n'avons que la qualité de l'argumentaire». Bulletin des médecins suisses. 2014; 95(45). 1681-5.
«En plus de la vie, d'une forte constitution et d'un lien immuable à la famille royale des Thembu, la seule chose que m'a donnée mon père à la naissance a été un nom, Rolihlahla. En xhosa, Rolihlahla signifie littéralement «tirer la branche d'un arbre), mais dans la langue courante, sa signification plus précise est «celui qui crée des problèmes`. Je ne crois pas que les noms déterminent la destinée ni que mon père ait deviné mon avenir d'une façon ou d'une autre, mais plus tard, des amis et des parents attribueront en plaisantant à mon nom de naissance les nombreuses tempêtes que j'ai déclenchées et endurées» [1].

C'est ainsi que débute l'autobiographie de Nelson Mandela Un long chemin vers la liberté (titre original Long Walk to Freedom) de 1994. Le premier président noir d'Afrique du Sud et lauréat du prix Nobel de la paix est un «fauteur de troubles» à plus d'un titre. Le cinq décembre marquera le premier anniversaire de sa mort. Cet événement doit être l'occasion de réfléchir à ses accomplissements exceptionnels dans les domaines politique, social et humain. Lui qui a lutté toute sa vie contre la discrimination raciale et l'injustice sociale a passé 27 longues années en détention, en tant que prisonnier politique. C'est en 1964 que Mandela, expert en droit et, à l'époque, dirigeant de l'African National Congress (ANC), est condamné. Dans des conditions très dures, il a par exemple cassé des cailloux sur l'île prison de Robben Island, située dans l'océan Atlantique en face de la ville du Cap. C'est là que Mandela a vécu la période la plus sombre de son histoire, marquée par la solitude, les humiliations et les travaux physiquement pénibles. Dans la chaleur estivale, la chaux que les prisonniers devaient creuser reflétait directement les rayons du soleil dans leurs yeux, frappant la rétine sensible. Mandela et ses compagnons d'infortune étaient en permanence menacés de cécité. Les «délits» comme la lecture clandestine des journaux étaient punis d'isolement et de privation de nourriture. Suite à son transfert à la prison de Pollsmoor au Cap, qui devait faire l'effet d'un hôtel cinq étoiles après Robben Island, le médecin diagnostiqua un début de tuberculose pulmonaire.

Bien que le quotidien carcéral éprouvant prive les détenus de leur humanité jusqu'à les ramener parfois à un état animal, Mandela ne perd jamais sa capacité à pardonner, qui se nourrit essentiellement de sa grande foi dans le bien. Parce qu'il parvient régulièrement à nouer un dialogue d'humanité, il ob- tient peu à peu de meilleures conditions de détention et des rencontres avec des représentants des autorités, de la politique et de la justice. Les détenus sont autorisés à faire du sport, jouer des pièces de théâtre et même suivre des études universitaires par correspondance. Ceux qui ont de l'instruction apprennent à lire et à écrire aux analphabètes. Mandela encourage même ses gardiens à entreprendre des études pour améliorer leurs perspectives d'évolution sociale.

Le 11 février 1990, Nelson Mandela est enfin libéré sur ordre du président de l'époque, Frederik de Klerk. Mais il ne part pas avant d'avoir salué et remercié ses gardiens. En 1993, Mandela et Frederik de Klerk reçoivent conjointement le prix Nobel de la paix en hommage à leur travail infatigable au service d'une Afrique du Sud nouvelle, fondée sur des valeurs de liberté, de réconciliation et d'égalité des droits des Noirs et des Blancs. Durant son mandat présidentiel, de 1994 à 1999, Mandela se bat pour de meilleurs soins de santé, qui tiennent notamment compte des besoins des enfants et des femmes enceintes. En 1996, tous les citoyens sud-africains obtiennent l'accès gratuit aux soins de santé primaires. Mandela fait en outre amener l'électricité et l'eau dans les bidonvilles, ce qui améliore considérablement les conditions de vie des Noirs, mais aussi leur santé, puisque de nombreuses maladies sont dues à des facteurs sociaux auxquels la classe politique devrait être plus attentive [2]. Symbole de la lutte anti-apartheid et humaniste, Mandela s'est attaqué à ces facteurs sociaux. Par son engagement dans le politique de la santé, bien sûr. Mais la «Madiba Magic» - c'est ainsi qu'on surnomme la puissante joie de vivre qui émanait de lui - était certainement aussi à l'œuvre. Tout comme en 1995, lorsqu'il est apparu aux Championnats du monde de rugby - une fête des Blancs, à laquelle les Sud-Africains noirs ne pouvaient pas s'identifier - arborant le maillot de l'équipe nationale et a encouragé cette dernière. Son amour de l'humanité se reflète dans ses actes et son attitude intellectuelle. Ceux qui maitrisent l'art du pardon aussi brillamment que Nelson Mandela sont libres, vivent la réconciliation et contribuent à rendre le monde meilleur.

Isabel Zwyssig*

* Isabel Zwyssig M.A. est rédactrice coordinatrice du Bulletin des médecins suisses depuis septembre de cette année. 